\title{
Modeling of the Radiation Doses during Dismantling of RBMK-1500 Reactor Pressurized Tanks from Emergency Core Cooling System
}

\author{
A. Simonis, P. Poskas, A. Sirvydas, and D. Grigaliuniene \\ Nuclear Engineering Laboratory, Lithuanian Energy Institute, Breslaujos g. 3, 44403 Kaunas, Lithuania \\ Correspondence should be addressed to A. Simonis; audrius@mail.lei.lt
}

Received 20 May 2013; Revised 14 August 2013; Accepted 21 August 2013

Academic Editor: Alejandro Clausse

Copyright (c) 2013 A. Simonis et al. This is an open access article distributed under the Creative Commons Attribution License, which permits unrestricted use, distribution, and reproduction in any medium, provided the original work is properly cited.

Decommissioning of the Ignalina Nuclear Power Plant involves multiple problems. One of them is personnel radiation safety during the performance of dismantling activities. In this paper, modeling results of radiation doses during the dismantling of the pressurized tank from the emergency core cooling system (ECCS PT) of RBMK-1500 reactor are presented. The radiological surveys indicate that the inner surface of the ECCS PT is contaminated with radioactive products of corrosion and sediments due to the radioactive water. The effective doses to the workers have been modeled for different strategies of ECCS PT dismantling. In order to select the optimal personnel radiation safety, the modeling has been performed by the means of computer code "VISIPLAN 3D ALARA Planning tool" developed by SCK CEN (Belgium). The impacts of dismantling tools, shielding types, and extract ventilation flow rate on effective doses during the dismantling of ECCS PT have been analyzed. The total effective personnel doses have been obtained by summarizing the effective personnel doses from various sources of exposure, that is, direct radiation from radioactive equipment, internal radiation due to inhalation of radioactive aerosols, and direct radiation from radioactive aerosols arising during hot cutting in premises. The uncertainty of the collective doses is also presented in this paper.

\section{Introduction}

Ignalina NPP is the only nuclear power plant in Lithuania. Ignalina NPP operated two similar RBMK-1500 units with installed capacity of $1500 \mathrm{MW}$ (each). They were commissioned in 1983 and 1987, and the original design lifetime was projected up to 2010 and 2015, respectively. However, the first unit was shut down at the end of 2004, and the second one was shut down at the end of 2009. The Lithuanian Government approved an immediate decommissioning strategy for the first unit of INPP $[1,2]$.

Building 117/1, where the emergency core cooling system (ECCS) is installed, is the first dismantling project at Ignalina NPP. After the shutdown of the first unit of INPP, the high pressure part of ECCS pressurized tanks (PT), big diameter pipes, fast acting valves, and the Helium Make-up Station became redundant and were no longer needed for safety or operational purposes and hence could be progressively dismantled. Contamination of internal surfaces of some equip- ment (big diameter pipes, small pipes, and ECCS PT) that had been in contact with the reactor core cooling water was detected [3].

Nowadays, due to enhancements in computer systems, the dismantling activities are planned using various types of software taking into account radiation fields. In 1999, SCK-SEN Laboratory in Belgium developed the computer code VISIPLAN [4] widely used to solve radiation protection problems (for analysis of direct radiation) such as handling of fiber-reinforced concrete container with conditioned radioactive waste [5], using conditional release of materials in the form of steel railway tracks [6], or modeling of intrusion scenario for deep geological repository [7]. In this paper, the direct exposure during the dismantling of the ECCS PT has been analyzed using VISIPLAN computer code. Furthermore, impacts of other radiation sources (internal inhalation exposure and external radiation from radioactive aerosols) have been also taken into account. 


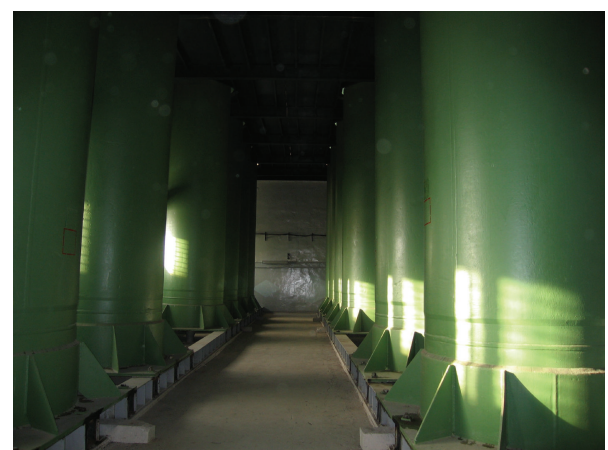

FIgURE 1: Photo of the ECCS PT in Building 117/1 [3].

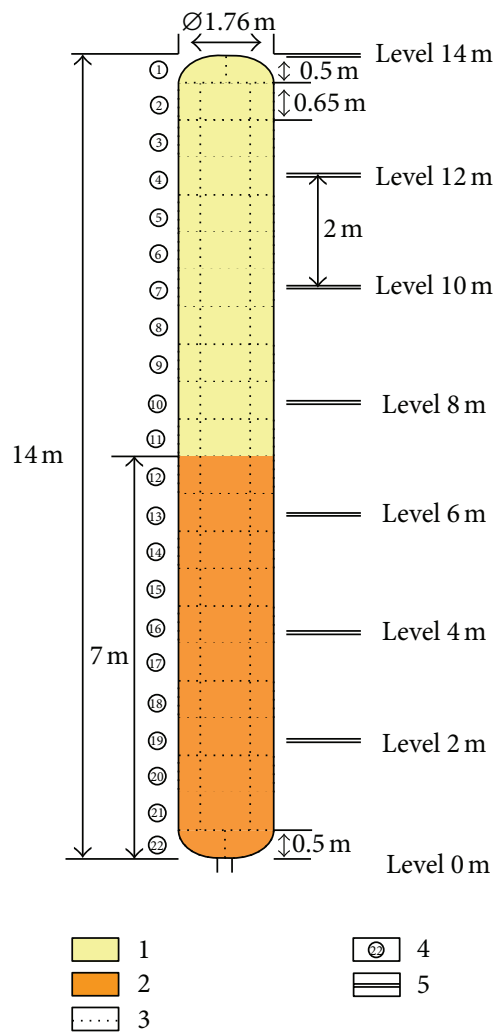

FIGURE 2: Model of ECCS PT dismantling.

\section{ECCS PT Dismantling Strategies and Used Technologies}

There are 16 ECCS PTs in Building 117/1 (see Figure 1). ECCS PT consists of a welded vertical cylinder with two ellipsoidal bottoms, support structure, nozzles, and a manhole. The outside diameter, height, and wall thickness are $1.76 \mathrm{~m}, 14 \mathrm{~m}$, and $0.08 \mathrm{~m}$, respectively. ECCS PT is made from carbon steel, and its mass is about 47.6 tons.

During the dismantling, the scaffolding was used. It has seven levels, and the height of one level was $2 \mathrm{~m}$. The dismantling scheme of ECCS PT is presented in Figure 2. The process of ECCS PT dismantling was as follows:

(a) cutting of the upper ellipsoidal bottom into two pieces: these pieces were lifted at once; (b) cutting of the ECCS PT cylinder body into 20 rings: the number of the rings was calculated based on the crane lifting capacity; each ring was cut into four parts;

(c) cutting of the ellipsoidal bottom and support structure of ECCS PT into two pieces, and these pieces were lifted at once.

Dose planning and forecasting is an important phase of ALARA principles implementation. Selection of proper usage methods of the dismantling equipment allows reducing the personnel collective dose.

During the operation, ECCS PTs were filled with water. Therefore, during the dismantling, they might be also filled with water, and they would perform the function of shielding against the direct radiation. During each ECCS PT part dismantling, the level of the water would be reduced up to the radial cut line. It has been assumed that neighboring ECCS PTs are empty during the dismantling:

(1) surface activity as at measurement point at level 7.2 (see Table 2);

(2) surface activity as at measurement point at level 0.0 (see Table 2);

(3) cut seam;

(4) number of ECCS PT parts;

(5) scaffolding and its level.

As mentioned above, the wall thickness of ECCS PT is $0.08 \mathrm{~m}$. During selection of the cutting equipment for this thickness, the plasma cutter has been considered impractical; thus the oxyacetylene cutting has been selected. The oxyacetylene cutting equipment with remote controlled torch is used worldwide in dismantling the equipment with round or plate surfaces. So, two cases of usage of the cutting equipment during the dismantling of ECCS PT have been analyzed, that is, usage of the automatic cutting (oxyacetylene cutting equipment with remote controlled machine torch) equipment and the manual oxyacetylene cutting equipment.

During the cutting of the ellipsoidal top and bottom, the manual cutting equipment should be used due to specific shape of the ECCS PT surface.

Cutting rate depends on the experience and skills of the worker performing the cutting operation. In our case, cutting rate of the manual cutting equipment has been selected $9 \pm$ $1 \mathrm{~m} / \mathrm{h}$ [8]. Cutting rate should increase using the automatic cutting equipment because the human factor is absent. So, the cutting rate selected for the automatic cutting equipment is $12 \pm 1 \mathrm{~m} / \mathrm{h}$.

It has been assumed that cutting $0.08 \mathrm{~m}$ wall thickness with the manual cutting equipment will produce a kerf of $0.0015 \pm 0.0005 \mathrm{~m}$ width; using the automatic cutting equipment, the kerf width will be $0.001 \pm 0.0005 \mathrm{~m}$.

It has been assumed that regardless of cutting equipment selection, two workers perform all dismantling works. For analysis, it has been assumed that the dismantling operations consist of preparation before each cutting and cutting activities. 
TABLE 1: Workers operations and corresponding duration for dose calculation.

\begin{tabular}{|c|c|c|c|}
\hline Number & Activity & $\begin{array}{l}\text { Duration of activity if the automatic } \\
\text { cutting equipment is used, min }\end{array}$ & $\begin{array}{l}\text { Duration of activity if the manual } \\
\text { cutting equipment is used, min }\end{array}$ \\
\hline$(1)$ & Preparation for cutting upper or lower ellipsoid & - & $2 \pm 0.5$ \\
\hline (2) & Cutting upper or lower ellipsoid into two pieces* & - & $18.6 \pm 2.0$ \\
\hline (3) & Preparation for radial cutting & $5 \pm 0.5$ & $3 \pm 0.5$ \\
\hline (4) & Radial cutting* & $27.8 \pm 2.3$ & $37.3 \pm 4.1$ \\
\hline (5) & Preparation for vertical cutting (four times) & $6 \pm 1$ & $2 \pm 0.5$ \\
\hline (6) & Vertical cutting (four times) ${ }^{*}$ & $13.1 \pm 1.1$ & $17.5 \pm 1.9$ \\
\hline
\end{tabular}

${ }^{*}$ Time is calculated based on cutting equipment rate.

TABLE 2: Contamination of internal surfaces of ECCS PT [3].

\begin{tabular}{lcccc}
\hline Nuclide & $\begin{array}{c}\text { Measurement point at level } 0.0 \\
\text { Surface contamination, } \mathrm{Bq} / \mathrm{cm}^{2}\end{array}$ & \multicolumn{2}{c}{$\begin{array}{c}\text { Measurement point at level }+7.2 \\
\%\end{array}$} \\
\hline Co-60 & 37.52 & 47 & 0 & 0 \\
Cs-137 & 42.91 & 53 & 25.58 & 100 \\
\hline Total & 80.43 & 100 & 25.58 & 100 \\
\hline
\end{tabular}

If the manual cutting equipment is used, both workers perform preparation works (marking the cutting line and preparation of the cutting equipment) before cutting. If the automatic cutting equipment is used, both workers mark the cutting line, mount the track, and prepare the cutting equipment during preparation works. It has been assumed that during preparation works the workers are close to ECCS $\mathrm{PT}$, that is, at $0.3 \mathrm{~m}$ distance from the outer surface. If the manual cutting equipment is used during the cutting, it has been assumed that both workers are at $0.3 \mathrm{~m}$, and if the automatic cutting equipment is used, workers are at $1 \mathrm{~m}$ distance from the ECCS PT surface.

Durations of the operations during the dismantling of ECCS PT are presented in Table 1.

Cutting of the contaminated equipment results in generation of radioactive aerosols. These aerosols are one of the radioactive sources that are detrimental to workers in case of inhalation. Inhalation of such aerosols causes the worker's internal exposure, and work in a radiological cloud results in external exposure.

Based on [9], it has been assumed that released respirable mass (radioactive aerosols) is $0.45 \pm 0.25 \%$ of the cut-out mass if the oxyacetylene cutting equipment is used. It is planned to use additional mobile filtration unit (MFU) to minimize volumetric activity in the workplace. So, two cases of usage of the ventilation type during the dismantling of ECCS PT have been analyzed, that is, usage of exhaust ventilation in a building (natural air flow rate is assumed to be $0.6 \pm 0.06 \mathrm{~m}^{3} / \mathrm{h}$ ) and usage of MFU (air flow rate is assumed to be $2500 \pm 250 \mathrm{~m}^{3} / \mathrm{h}$ ). In all cases, it is conservatively assumed that the workers do not use respiratory protection equipment during the dismantling of ECCS PT.

\section{Methodology of Dose Modeling}

Using the existing geometrical data and taking into account the influence of the neighboring ECCS PTs, the basic 3D model with four ECCS PTs has been designed with VISIPLAN (see Figure 3).

In the model, it has been assumed that the walls for all ECCS PT are cylinders with normally shaped ends. The body length is $14 \mathrm{~m}$, the outer diameter is $1.76 \mathrm{~m}$, and the wall thickness is $0.08 \mathrm{~m}$ with carbon steel density of $7.9 \mathrm{t} / \mathrm{m}^{3}$.

As it has been already indicated in this paper, computer code VISIPLAN has been used to model direct radiation. This code is intended for estimation of gamma radiation dose rates in simple and complex 3D geometries. In this code, the calculation of dose rate for radiation sources is based on "point kernel" method.

The photon fluence rate at the dose point near the volume source can be determined considering the volume source consisting of a number of point sources [4].

The photon fluence rate is calculated using the following formula:

$$
\varphi=\int_{V} \frac{S \cdot B \cdot e^{-b}}{4 \cdot \pi \cdot \rho^{2}} d V
$$

where $S$ is the source strength representing the number of photons emitted by the source per unit time and volume, $\mathrm{n} \cdot \mathrm{s}^{-1} \cdot \mathrm{cm}^{-3}, B$ is the build-up factor, $b$ is the mean free paths (the attenuation effectiveness of a shield), $\rho$ is the distance from a point source, and $V$ is the source volume.

Based on the photon fluence rate at a point, computer code calculates the effective dose depending on the dose conversion factors:

$$
D_{\mathrm{dir}}=t \cdot \sum_{i} h_{i} \cdot \varphi_{i}
$$

where $h_{i}$ is the dose conversion coefficient [10] for photons of energy $i, \varphi$ is the fluence rate of the photons at energy $i$, and $t$ is the time during which the worker is exposed to ionizing radiation from the radioactive equipment, $h$. 


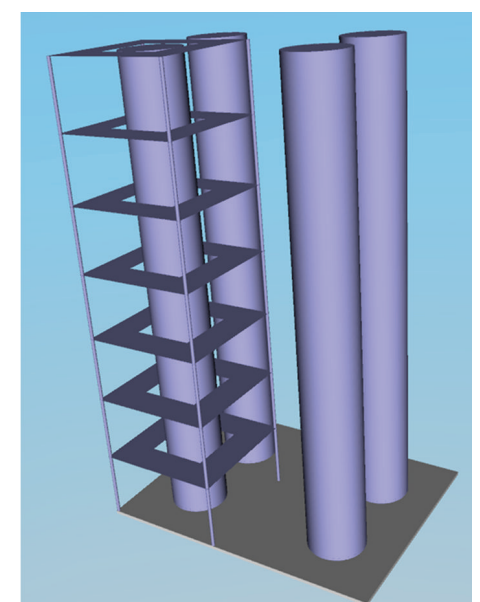

FIgURE 3: View of four ECCS PTs 3D computer model.

According to radiological measurements performed by INPP staff in 2007, the ECCS PT internal surface is contaminated. 16 ECCS PTs are divided into two branches, and thus during the radiological surveys, the internal contamination of one ECCS PT from each branch was measured. To define the contamination level, two measurement points at different levels were selected for these ECCS PTs. One measurement point was at the very bottom (level 0.0 ), and the other was at $7.2 \mathrm{~m}$ (middle height of PT). Contamination of internal surfaces of most contaminated ECCS PTs is presented in Table 2, and the localization of the assigned contamination surfaces in the model is shown in Figure 2.

The radioactive source has been modeled as a cylindrical homogeneous contamination (thickness $2 \mathrm{~mm}$ ) with density $7.9 \mathrm{t} / \mathrm{m}^{3}$. In the model, it has been conservatively assumed that the contamination up to $7 \mathrm{~m}$ is the same as that at the level 0.0 , and the contamination up to $14 \mathrm{~m}$ is the same as that at the level 7.2. In the modeling, it has been assumed that four ECCS PTs cause dose effect to the workers. In modeling, the contamination surface of ECCS PT has been divided into 24 sources, that is, 22 cylindrical sources and two sources of circle shape.

Taking into account the influence of the neighboring ECCS PT on the workers, the dose rates at eight positions at each level have been modeled. So, dose rate has been modeled at all in 352 dose points. During uncertainty analysis, it is assumed that the received dose rate at each dose point varies $\pm 30 \%$.

The inhalation of the effective dose by worker is calculated on the basis of the methodology presented in IAEA Safety Guide [11]. The submersion dose is calculated on the basis of the methodology presented in Federal Guidance Report [12].

Air concentration of each radionuclide during cutting process has been calculated using the following formula:

$$
\bar{C}_{i}=z \cdot l \cdot A_{i} \cdot f \cdot t^{-1} \cdot Q^{-1}
$$

where $z$ is the kerf width, $\mathrm{cm}, l$ is the kerf length, $\mathrm{cm}, A_{i}$ is the surface activity of the $i$ th radionuclide, $\mathrm{Bq} \cdot \mathrm{cm}^{-2}, f$ is the fraction of removed material that becomes indoor dust, $t$ is the time to cut material, $h$, and $Q$ is the flow of air from the room to the outside, $\mathrm{m}^{3} \cdot \mathrm{h}^{-1}$.

Based on Table 2 data, the activity of the ECCS PT internal surface has been calculated for 26 radionuclides using scaling factor defined for ECCS equipment [13].

To receive total effective collective dose, the collective doses (for two workers) from direct radiation, inhalation, and submersion are summed.

For uncertainty analysis of collective dose modeling, the computer code MATLAB has been used. 10000 simulations have been performed. It has been assumed that all parameters have linear distribution.

\section{Results and Discussion}

Using VISIPLAN, the dose rate map (isodoses) of the external ECCS PT side has been obtained (see Figure 4). As the figure demonstrates, the dose rate at the lower part of ECCS PT is the highest and reaches up to $1 E-4 \mathrm{mSv} / \mathrm{h}$. At the upper part of ECCS PT, the dose rates are approximately 100 times smaller than those at the lower part.

The modeling results show that by using the automatic cutting equipment, the average duration of one ECCS PT dismantling will be $19 \mathrm{~h}$ (standard deviation 0.96). Using the manual cutting equipment, the average duration will be $21.8 \mathrm{~h}$ (standard deviation 0.57).

The comparison of collective doses from direct radiation for two workers after dismantling one ECCS PT using different dismantling strategies is presented in Figure 5. As it is shown in this figure, the average collective dose from direct radiation can be decreased by approximately $10 \%$ if during the dismantling of the ECCS PT it is filled with water. The collective dose from direct radiation decreases approximately $20 \%$ if the automatic cutting equipment is used instead of the manual.

The direct exposure dose rate contribution from the neighboring ECCS PTs depends on the position of the worker and varies from $1 \%$ to $60 \%$.

Inhalation dose and submersion dose modeling results show that the average collective dose is approximately 1.5 times lower if the automatic cutting equipment is used instead of the manual cutting equipment in case building exhaust ventilation and/or MFU are used (see Figure 6). If building exhaust ventilation is used (see Figure 6(a)), the average collective inhalation dose is approximately 46-62 times higher than the average collective dose from direct radiation (see Figure 5). If MFU is used (see Figure 6(b)), the average collective inhalation dose is approximately 6690 times lower than the average collective dose from direct radiation (see Figure 5).

If building exhaust ventilation is used (see Figure 6(c)), the average collective submersion dose is approximately 22.8 times lower than the average collective dose from direct radiation (see Figure 5). If MFU is used (see Figure 6(d)), 


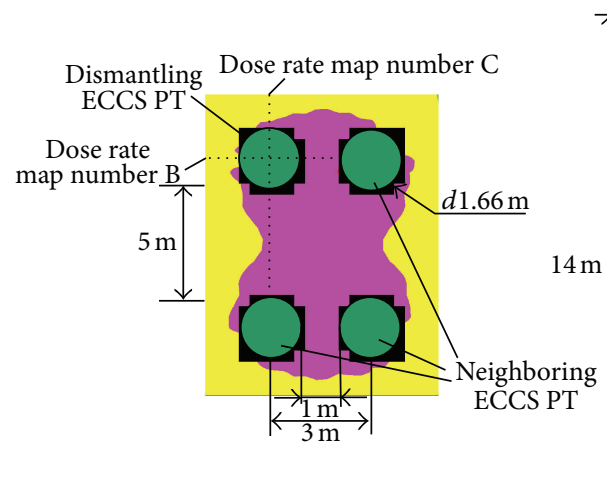

Dose rate map number A

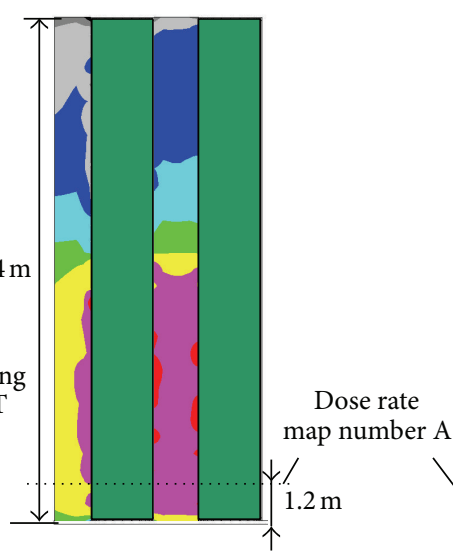

Dose rate map number B

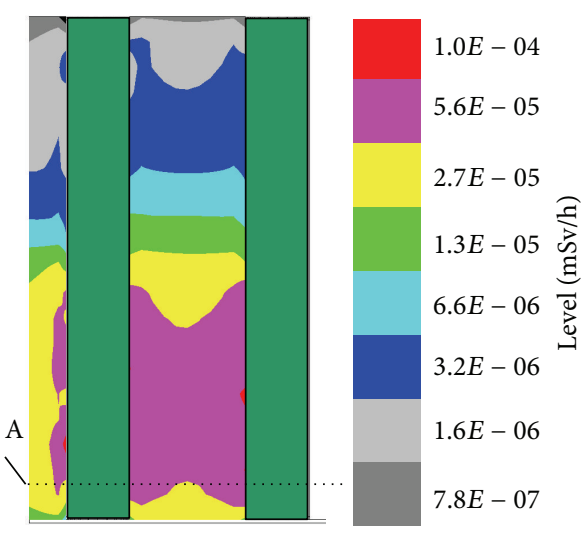

Dose rate map number $\mathrm{C}$

FIGURE 4: Dose rate maps.

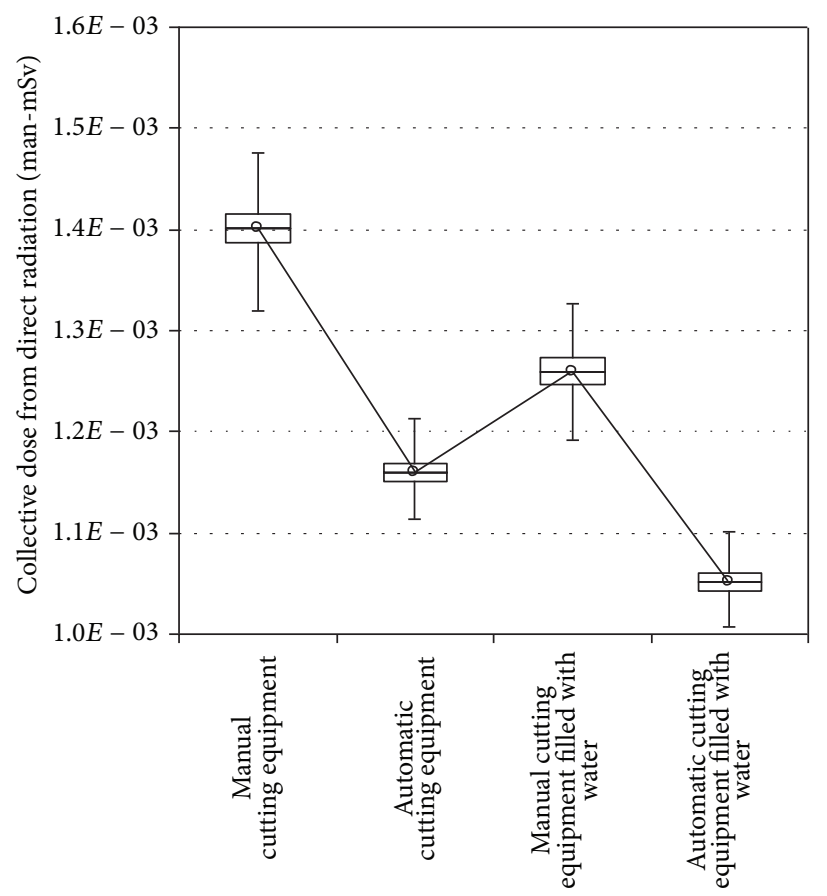

FIGURE 5: Whisker diagrams of collective dose from direct radiation (ends of whiskers present minimum and maximum values; circles present average).

the average collective submersion dose is approximately 8600-1200 times lower than the average collective dose from direct radiation (see Figure 5).

As shown in Figure 6, the average collective submersion dose is approximately 130 times lower than the collective inhalation dose. Using MFU, the collective inhalation dose and collective submersion dose decrease four thousand times.

The total average effective collective dose is obtained by summarizing the collective doses from direct radiation, inhalation, and submersion. The modeling results show that taking into account all these sources of exposures during the ECCS PT dismantling and using building exhaust ventilation, the biggest part of the average collective dose is from the inhalation radiation (95-96\%). Direct radiation dose contributes 3-4\% to the total effective dose. So, submersion dose contributes a small part $(<1 \%)$. Using MFU, the inhalation and submersion doses are practically eliminated, and the total effective dose consists mainly (99\%) of direct radiation.

Based on the Lithuanian Hygiene Standard [14], the occupational exposure of any worker shall be controlled in order not to exceed the dose limits. One of the dose limits is an effective dose of $20 \mathrm{mSv}$ per year averaged over five consecutive years. Assuming that there are 245 working days per year and 6 effective working hours per day, the dose limit per hour will be $0.014 \mathrm{mSv}$. Individual doses (taking into account the dismantling duration of the ECCS PT) have 


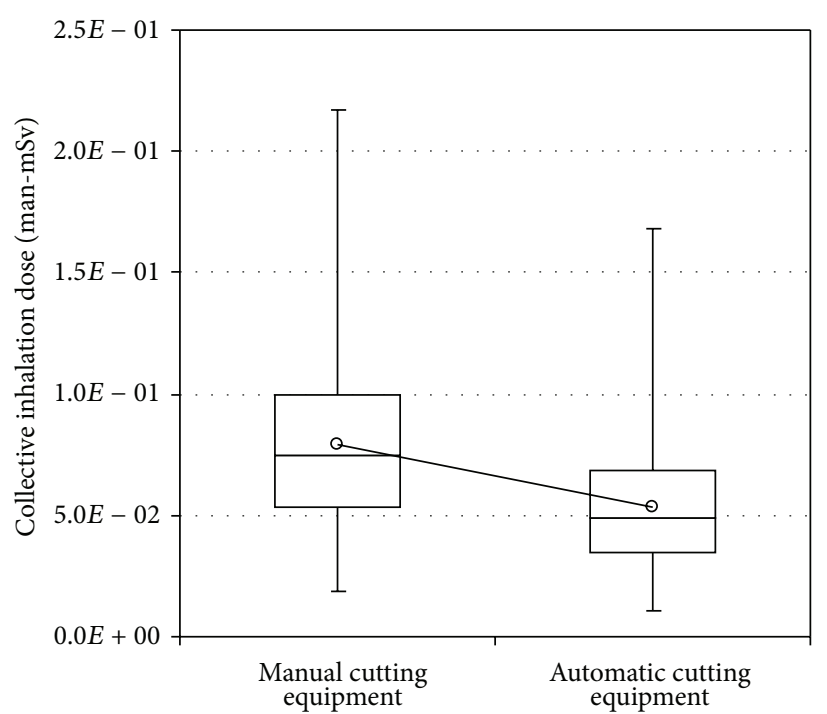

(a)

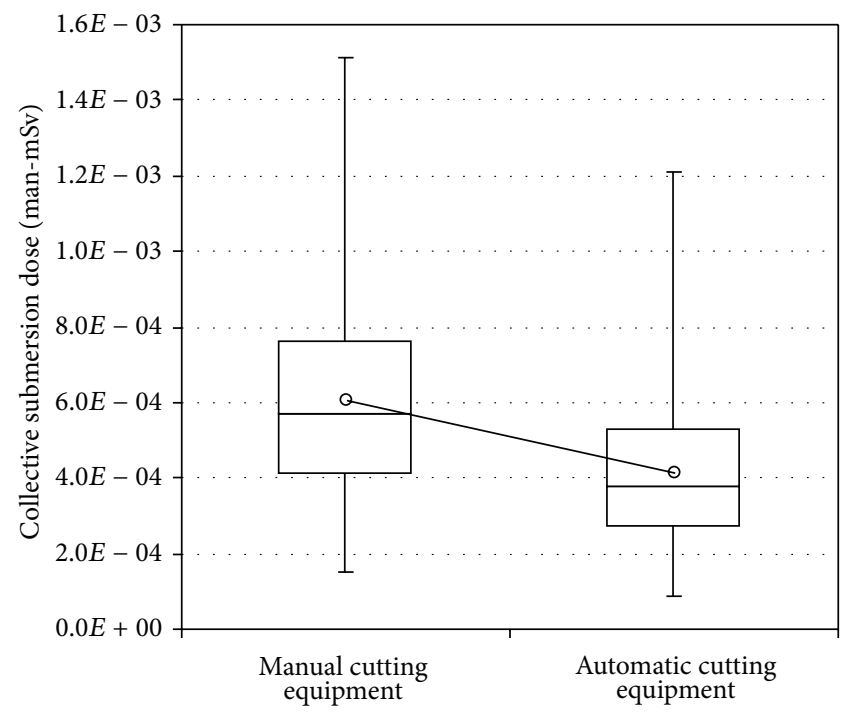

(c)

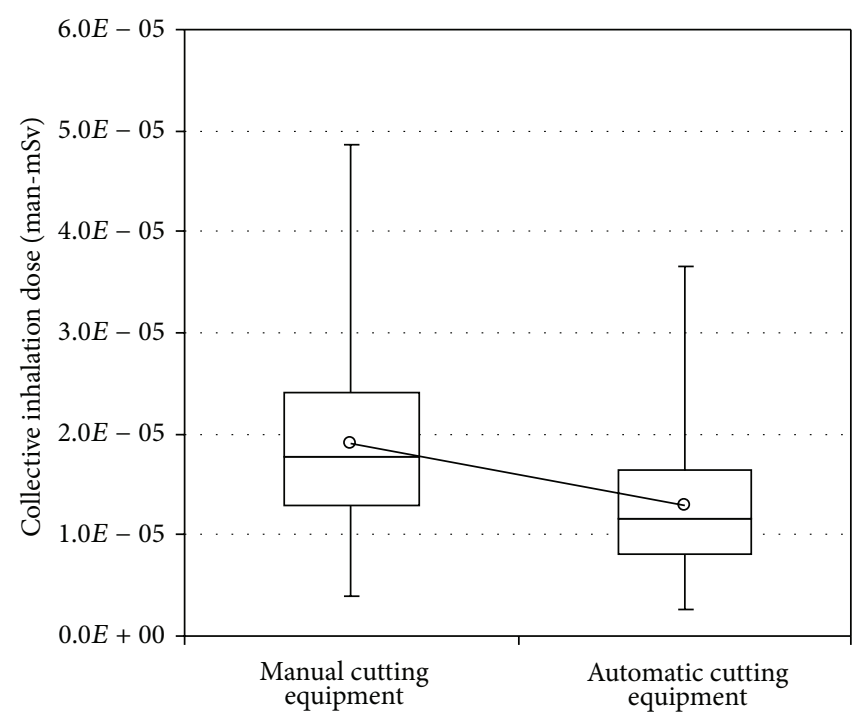

(b)

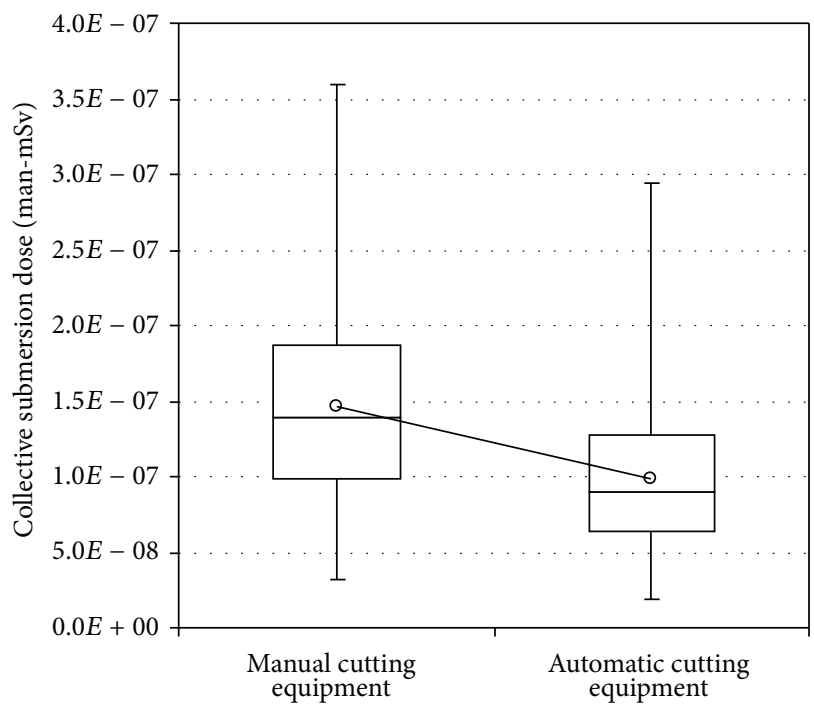

(d)

FIGURE 6: Whisker diagrams (ends of whiskers present minimum and maximum values; circles present average). (a) Collective inhalation doses using building exhaust ventilation, (b) collective inhalation doses using MFU, (c) collective submersion doses using building exhaust ventilation, and (d) collective submersion dose using MFU.

been compared with the dose limit for each analysed case, and it has been discovered that the individual doses do not exceed the dose limit. Using building exhaust ventilation, the individual dose for one worker is $14 \%$ of the dose limit, and for another worker it is $11 \%$. Using MFU during the dismantling of the ECCS PT, the individual doses for both workers decrease to $0.26-0.21 \%$ of the dose limit. If during the dismantling the MFU is used and the ECCS PT is filled with water, the individual doses decrease to $0.24-0.19 \%$ of the dose limit.

The comparison of the average collective doses for each analyzed case if using MFU during the dismantling of ECCS PT is presented in Figure 7. The figure demonstrates that using the automatic cutting equipment with MFU, due to the higher cutting rate, the average collective effective dose can be decreased by $17 \%$ in comparison with the manual cutting equipment. Average collective effective dose can be decreased by $10 \%$ if during its dismantling the ECCS PT is filled with water. Average collective effective dose can be decreased by $25 \%$ if during its dismantling the ECCS PT is filled with water, and automatic cutting equipment and MFU are used. Considering radiation protection, this case is the preferred option.

According to the strategy, the amount of radioactive waste will increase (radioactive water will be formatted), if during the dismantling the ECCS PT is filled with water. This is not acceptable from the radioactive waste management point of view. Taking into account radiation protection and waste 


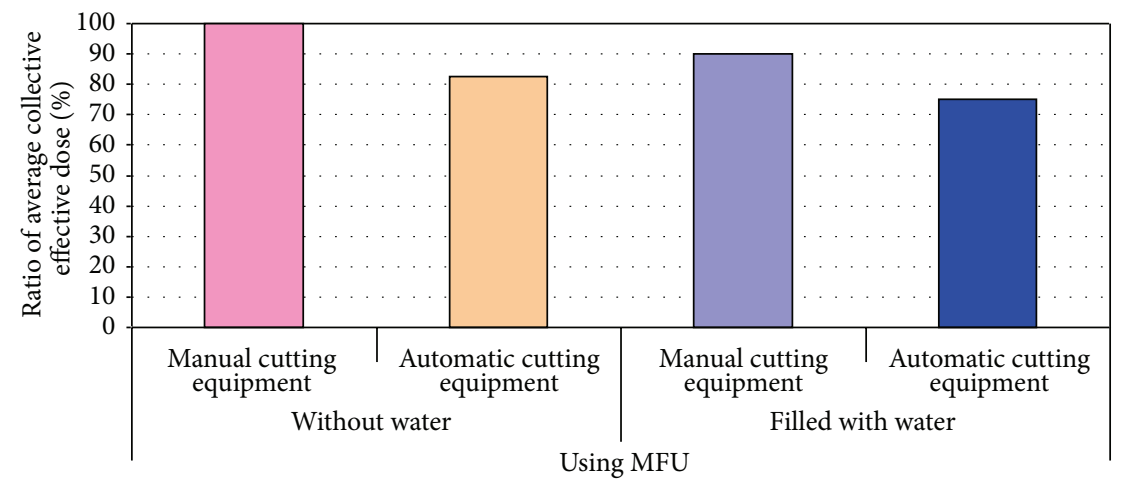

FIGURE 7: The comparison of the collective effective doses if MFU is used during dismantling of the ECCS PT.

management views, it is recommended to use MFU and automatic cutting equipment during the dismantling of the ECCS PT.

\section{Conclusions}

After analysis of the modeling results on exposure of the workers during the dismantling of the pressurized tank from emergency core cooling system (ECCS PT), the following conclusions have been drawn.

(1) Using building exhaust ventilation, inhalation dose contributes to the total effective dose 95-96\%, direct radiation from equipment contributes $3-4 \%$, and submersion dose contributes only $<1 \%$.

(2) Using mobile filtration unit, the inhalation and submersion doses are practically eliminated, and the total effective dose consists mainly (99\%) of direct radiation. In this case, average collective effective dose can be decreased by approximately $97 \%$.

(3) Using mobile filtration unit, average collective effective dose can be decreased by $17 \%$ if automatic gas cutting equipment is used instead of the manual cutting equipment.

(4) Using mobile filtration unit and manual cutting equipment, average collective effective dose can be decreased by $10 \%$ if during the dismantling of the ECCS PT it is filled with water.

(5) Using mobile filtration unit and automatic cutting equipment instead of manual cutting equipment, average collective effective dose can be decreased by $25 \%$ if during the dismantling of the ECCS PT it is filled with water.

(6) The individual doses for the analysed dismantling strategies do not exceed the dose limit.

(7) During the dismantling of the ECCS PT, it is recommended to use mobile filtration unit and automatic cutting equipment.

\section{References}

[1] The Republic of Lithuania Parliament Decision No. IX-1130, "On Approval of National Energy Strategy," State news, No. 994397, October 2002.

[2] The Republic of Lithuania Government Resolution No. 1848, "On State Enterprise Ignalina NPP First Unit Decommissioning Concept," State news, No. 114-5095, November 2002.

[3] Environment Impact Assessment Report, Ignalina NPP Building 117/1 Equipment Decontamination and Dismantling, VT Nuclear Services Ltd. and Lithuanian Energy Institute (Nuclear Engineering Laboratory), 2008.

[4] F. Vermeersch, Visiplan 3D Alara Planning Tool, User's guide, SCK CEN, Mol, Belgium, 2005.

[5] M. Panik and M. Zachar, "Dose assessment of personnel handling conditioned radioactive waste," in Proceedings of the 12th International Conference on Environment Remediation and Radioactive Waste Management (ICEM '09), Liverpool, UK, October 2009.

[6] P. Tatranský and V. Nečas, "Conditional release of materials from decommissioning process into the environment in the form of steel railway tracks," Nuclear Engineering and Design, vol. 239, no. 6, pp. 1155-1161, 2009.

[7] J. Pritrsky and F. Ondra, "Impact of the alternative fuel cycles on the long term safety of deep geological repository," in Proceedings of the 16th symposium of AER on VVER Reactor Physics and Reactor Safety, Bratislava, Slovakia, September 2006.

[8] "Gas Safe Ltd. in association with BOC," http://www.gassafegear.co.uk.

[9] M. A. Ebadian and S. K. Dua, "Size distribution and rate of production of airborne particulate matter generated during metal cutting," Final Report, HCET, New Port Richey, Fla, USA, 2001.

[10] International Commission on Radiological Protection (ICRP 51), "Data for use in protection against external radiation," A Report of A TAsk Group of Committee 3 of the ICRP, Annals of the ICRP, 1987.

[11] IAEA Safety Guide, No. RS-G-1.2, Assessment of Occupational Exposure due to Intakes of Radionuclides, IAEA Safety Guide, No. RS-G-1.2, Vienna, Austria, 1999.

[12] External Exposure to Radionuclides in Air, Water, sand Soil, Federal Guidance Report No. 12, USA, 1993.

[13] V. Remeikis, A. Plukis, L. Juodis et al., "Study of the nuclide inventory of operational radioactive waste for the RBMK-1500 
reactor," Nuclear Engineering and Design, vol. 239, no. 4, pp. 813818, 2009.

[14] Lithuanian Hygiene Standard HN 73, "Basic Standard of Radiation Protection," The Minister of Health Care, State news, No. 11-388, December 2001. 


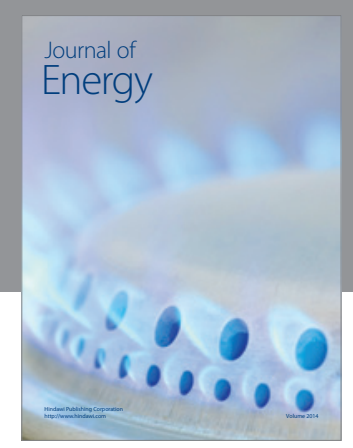

Journal of

Industrial Engineering
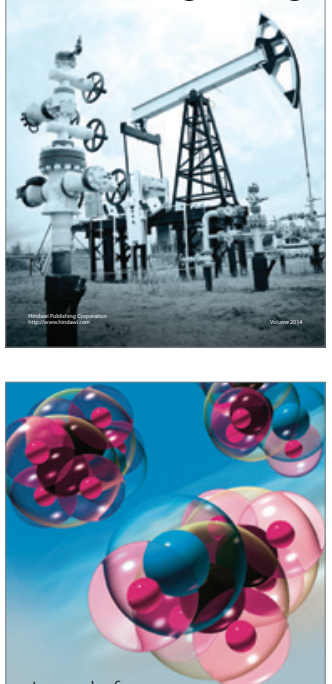

Fuels
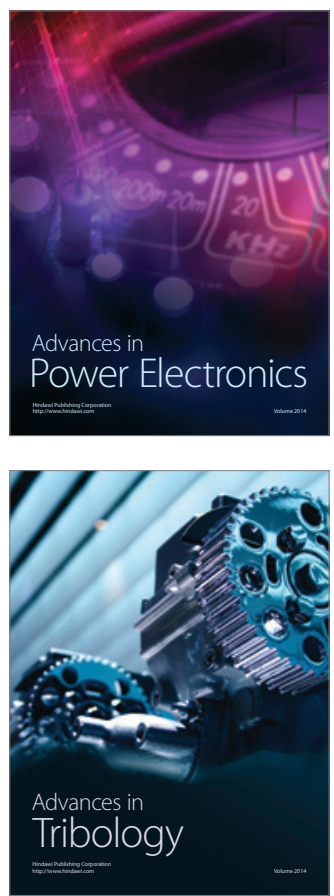

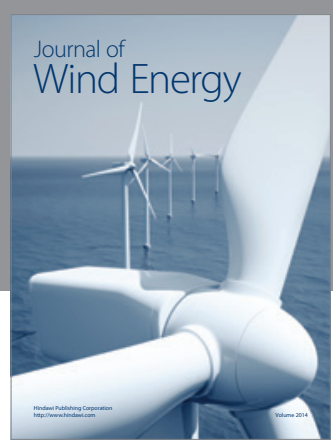

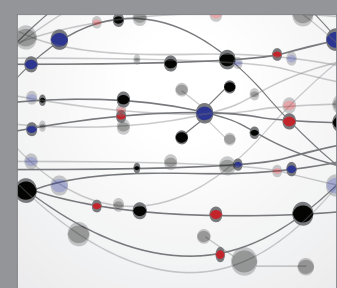

The Scientific World Journal

Submit your manuscripts at http://www.hindawi.com

Journal of

Structures
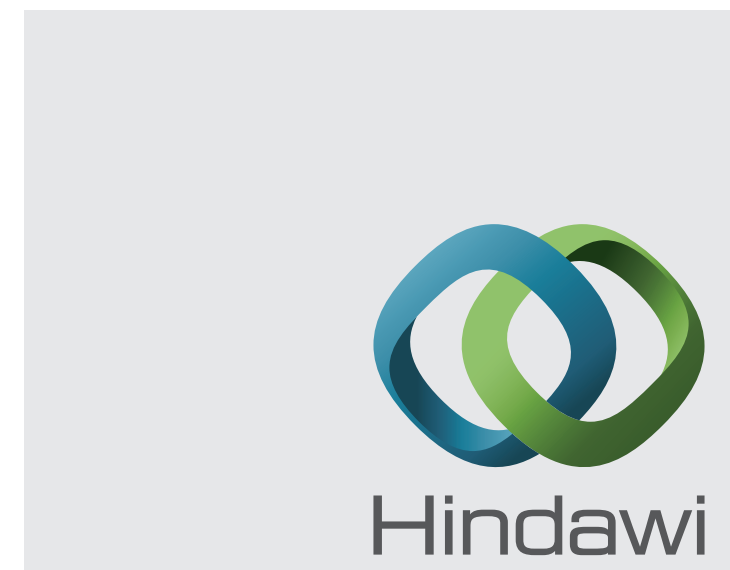

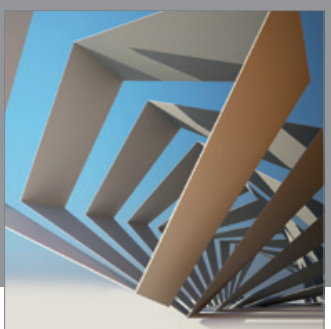

Rotating

Machinery
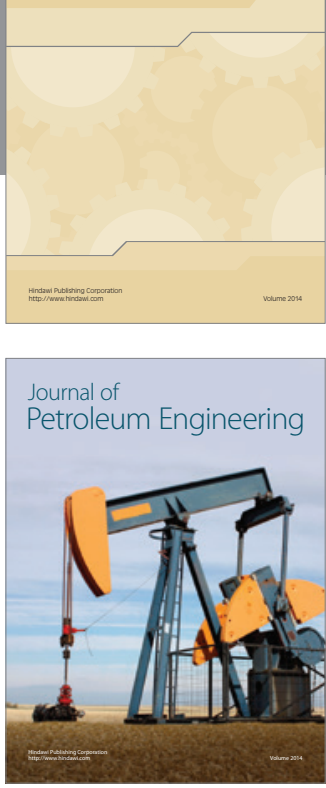

Journal of

Solar Energy
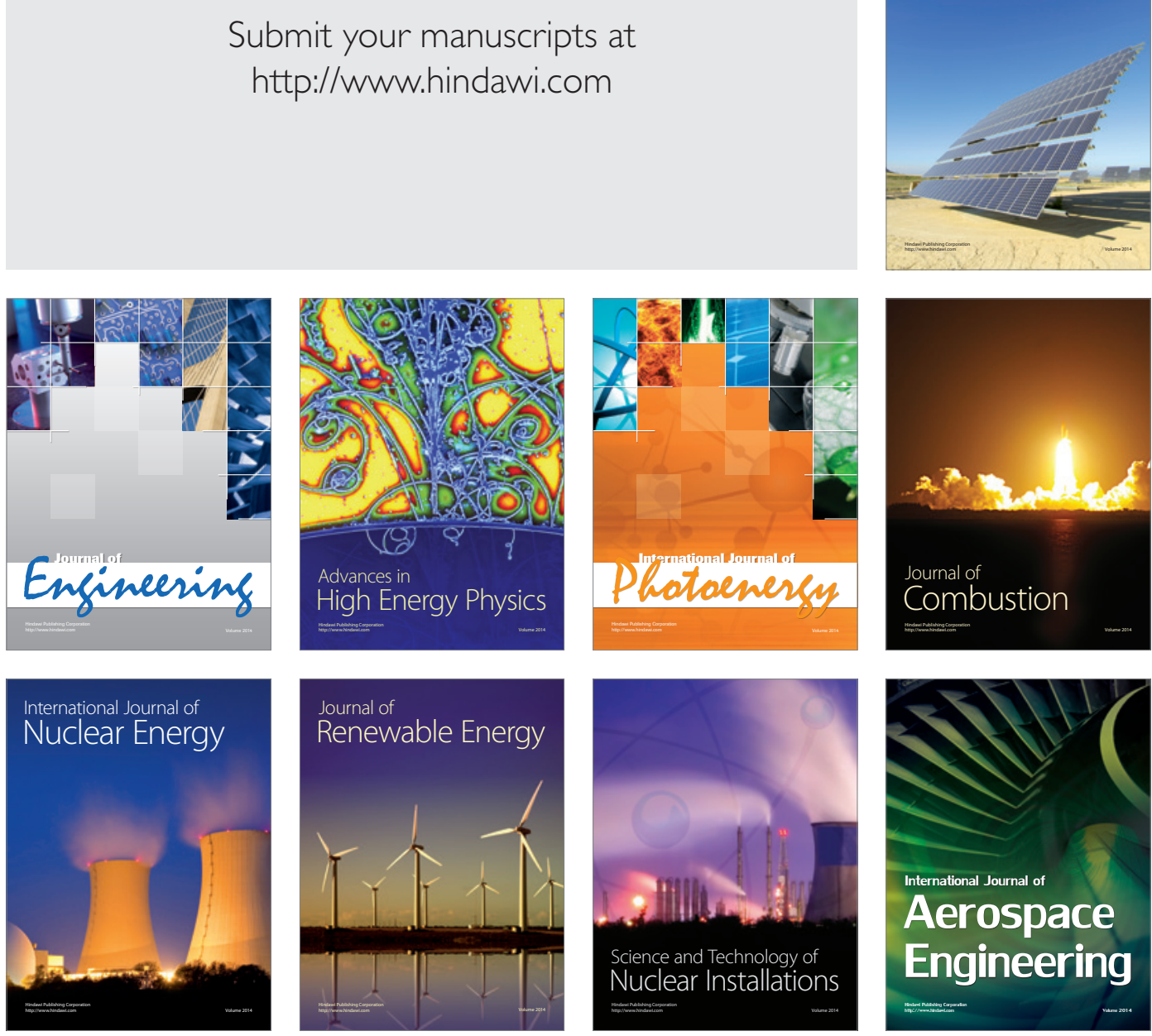